\title{
TO IMPROVE THE QUALITY OF LEARNING TEACHERS USING FRIENDLY SUPERVISION
}

\author{
Hiliyati Yus \\ SD Negeri 21 Pekanbaru, Indonesia \\ hiliyatiyus67@gmail.com
}

\begin{abstract}
Friendly supervision conducted by principals is basically an effort to improve the quality of education and teaching in schools with core teaching programs supported by other elements such as teachers, facilities and infrastructure, curriculum, teaching and assessment systems. This research method is a school action research study subject of three teachers in class VI with the results of the study seen in the completeness of the administration of learning owned by teachers in the first cycle the average value is 66 with less categories, while the completeness of the administration of learning owned by teachers in the second cycle average the average value is 87 with a very good category. In the implementation of learning activities carried out by teachers in the first cycle the average value was 77.33 with enough categories, increasing in the second cycle with an average value of 90 with good categories. It was concluded that friendly supervision was effectively carried out in improving the quality of teacher learning.
\end{abstract}

Keywords: learning quality, friendly supervision

\section{PENINGKATAN KUALITAS PEMBELAJARAN GURU DENGAN MENGGUNAKAN SUPERVISI BERSAHABAT}

\begin{abstract}
ABSTRAK
Supervisi bersahabat yang dilakukan kepala sekolah pada dasarnya adalah upaya untuk meningkatkan mutu pendidikan dan pengajaran di sekolah yang berintikan program pengajaran dengan ditunjang oleh unsur-unsur lain seperti guru, sarana dan prasarana, kurikulum, sistem pengajaran dan penilaian. Metode penelitian ini merupakan penelitian tindakan sekolah dengan subjek penelitian tiga orang guru kelas VI. Hasil penelitian dilihat pada kelengkapan administrasi pembelajaran yang dimiliki guru pada siklus I rata-rata nilainya adalah 66 dengan kategori kurang, sedangkan kelengkapan administrasi pembelajaran yang dimiliki guru pada siklus II rata-rata nilainya adalah 87 dengan kategori amat baik. Pada kegiatan pelaksanaan pembelajaran yang dilakukan guru di siklus I rata-rata nilainya adalah 77.33 dengan kategori cukup, meningkat pada siklus II dengan rata-rata nilai menjadi 90 dengan kategori baik. Maka disimpulkan bahwa supervisi bersahabat efektif dilakukan dalam meningkatkan kualitas pembelajaran guru.
\end{abstract}

Kata Kunci: kualitas pembelajaran, supervisi bersahabat

\begin{tabular}{|c|c|c|}
\hline Submitted & Accepted & Published \\
\hline 29 Juli 2020 & 04 September 2020 & 24 September 2020 \\
\hline
\end{tabular}

\begin{tabular}{|l|c|c|c|}
\hline Citation & $:$ & $\begin{array}{c}\text { Yus, H. (2020). To Improve The Quality Of Learning Teachers Using Friendly Supervision. Jurnal PAJAR (Pendidikan } \\
\text { dan Pengajaran), 4(5), 950-956. DOI : http://dx.doi.org/10.33578/pjr.v4i5.8075. }\end{array}$ \\
\hline
\end{tabular}

\section{PENDAHULUAN}

Kepala sekolah merupakan pemimpin dan manajer yang sangat memilih dinamika sekolah menuju gerbang kesuksesan dan kemajuan disegala bidang pendidikan (Arikunto, 2009). Kepala sekolah memiliki tugas memadukan unsurunsur sekolah dengan memperhatikan kultur dan lingkungan budayanya yang menjadi syarat terciptanya sekolah efektif (Slameto, 2016). Berbagai pengetahuan dan keterampilan diperlukan dalam penyusunan rencana supervisi yang efektif. Faktor mana yang lebih diperlukan, tergantung dari situasi, kondisi tempat menyusun rencana itu, dan tujuan yang akan dicapai. Tugas utama kepala sekolah merupakan (a) menyusun program kerja, visi misi seklolah, tujuan sekolah, menyusun RKS dan RKAS, (b) membimbing guru, memberdayakan peran serta masyarakat dan kemitraan sekolah, (c) melaksanakan supervisi, 
melaksanakan evaluasi diri sekolah (EDS), dan mengevaluasi pendayagunaan pendidik dan tenaga kendidikan sekolah (Mulyasa, 2003).

Sasaran domain supervisi pengajaran adalah hubungan pengembangan staf dengan inservice education, perbedaan pengembangan staf dengan in-service education, asumsi pentingnya in-service education, tiga supervisor dalam inservice education, kelemahan in-service education, ciri-ciri in-service education, dan mengenai mengontrol in-service education (Olivia, 1984; Slameto, 2016). In-service education bagian dari pengembangan staf yang dibagi dalam dua kategori yang staffing yang terdiri dari kegiatan selecting, assigning, evaluating, reticing, dismissing staf, dan trainin (Danumihardja, 2009). Upaya meningkatkan kualitas pembelajaran guru merupakan komponen sumber daya manusia yang harus dibina dan dikembangkan terus menerus. Potensi sumber daya guru itu perlu terus bertumbuh dan berkembang agar dapat melakukan fungsinya secara potensial. Selain itu pengaruh perubahan yang serba cepat mendorong guru-guru untuk terus-menerus belajar menyesuaikan diri dengan perkembangan ilmu pengetahuan dan teknologi, dan lingkungan (Rachmawati, 2016).

Supervisi yang dilakukan kepala sekolah pada dasarnya adalah upaya untuk meningkatkan mutu pendidikan dan pengajaran di sekolah yang berintikan program pengajaran dengan ditunjang oleh unsur-unsur lain seperti guru, sarana dan prasarana, kurikulum, sistem pengajaran dan penilaian. Melaksanakan supervisi bertugas dan bertanggung jawab memperhatikan perkembangan unsur-unsur tersebut secara berkelanjutan (Mulyana, 2002). Salah satu kompetensi kepala sekolah yang cukup krusial bahwa kepala sekolah harus mempunyai kemampuan dalam merencanakan supervisi akademik dan menindaklanjuti hasil supervisi tersebut kepada guru untuk meningkatkan kualitas pembelajaran. Hal ini menuntut kepala sekolah harus memiliki kemampuan yang lebih sebagai seorang supervisor (Tatang, 2016). Oleh karena itu, untuk meningkatkan kualitas pembelajaran di sekolah, mau tidak mau, kepala sekolah harus melaksanakan tugas hariannya, salah satunya yaitu melaksanakan supervisi kegiatan belajar di kelas yang telah dilakukan oleh guru.

Supervisi kelas adalah serangkaian kegiatan yang akan dilakukan oleh kepala sekolah untuk mengawasi tentang: setumpuk pembuatan administrasi kelas, akan diawasi dan dilihat kelemahan-kelemahannya selama mengajar, setelah itu akan menerima banyak nasehat yang berkaitan dengan tugas mengajar maupun perilaku guru pada umumnya ini yang menjadi ketakutan seorang guru sehingga praktik pembelajaran yang sudah terbiasa akan terlihat canggung sehingga mempengaruhi kemampuan guru dalam kualitas pembelajaran di kelas. Supervisi bersahabat merupakan pengawasan kepala sekolah dengan memberikan pendekatan secara kooperatif kepada guru-guru supaya tidak memberikan kesan ketakutan saat dilakukan supervisi di kelas (Soepardi, 2000).

Sintaks (urutan langkah) supervisi kelas bersahabat ada 3 tahapan dalam melaksanakan supervisi kelas yang bersahabat, yakni: 1) Tahap sebelum melakukan supervisi kelas; 2) Tahap Pelaksanaan Supervisi Kelas; 3) Tahap setelah supervisi kelas (PSBG, 2008). Pada tahap sebelum supervisi kelas, hal-hal yang harus dilakukan oleh seorang kepala sekolah adalah sebagai berikut: 1) Buatlah kesepakatan kapan akan dilakukan supervisi kelas dengan guru yang bersangkutan; 2) Diskusikan materi pelajaran apa yang akan diajarkan pada saat supervisi kelas; 3) Bantulah dalam membuat persiapan mengajar dengan memberikan masukan-masukan yang lebih baik; 4) Yakinkan pada guru yang bersangkutan bahwa kedatangan anda (supervisor) bukan akan menilai atau mengawasi namun anda datang akan memberikan bantuan teknis yang diperlukan oleh guru; 5) Buatlah kesepakatan untuk membagi peran antara anda (supervisor) dengan guru. Anda dapat memposisikan diri dalam 2 peran:

a. Sebagai Tim Pengajar bersama-sama guru, sebagai asisten guru yang sedang mengajar, misalnya bertugas membagikan lembar kerja, ikut mengkondisikan siswa dalam kelompok, membantu dalam kerja kelompok dsb.

b. Sebagai pengamat 
Pada tahap pelaksanaan supervisi kelas, hal-hal yang harus dilakukan oleh seorang pengawas atau kepala sekolah adalah sebagai berikut;

Pada tahap setelah supervisi kelas, hal-hal yang harus dilakukan oleh seorang kepala sekolah melakukan diskusi bersama guru dengan mematuhi 5 langkah berikut;

a. Tunjukkan sikap menghargai (tuliskan komentar anda dibawah ini), misalkan: Saya suka dengan kegiatan praktis yang bapak/Ibu lakukan tadi. Siswa benar-benar terlibat dalam kegiatan.

b. Tanyakan refleksi diri yang penting (tuliskan tanggapan guru tersebut dibawah ini) misalkan; Bagaimana perasaan anda selama proses pembelajaran tadi? Apakah anda sudah puas?

c. Masihkah ada kekurangan yang anda lakukan selama proses pembelajaran tadi, dibagian mana saja?

d. Tanyakan peningkatan yang ingin dilakukan oleh guru tersebut (tulis tanggapan yang diberikan oleh guru tersebut) misalnya; Hal apakah yang anda ingin lakukan secara berbeda bila anda melakukan pelajaran itu kembali? Mengapa? Bagaimana cara anda meningkatkan keaktifan/ kreativitas/keefektifan/ kesenangan dari pelajaran tersebut?

e. Berikan saran atau arahkan diskusi ke masalah lain yang belum disebutkan yang mungkin masih bisa ditingkatkan (tuliskan saran anda dibawah) Misalnya: kelompok yang dipojok tampaknya tidak belajar banyak? Apa yang bisa anda lakukan untuk membantu mereka? Apakah menurut anda alat bantu belajar anda banyak membantu? Bagaimanakah cara meningkatkannya?

Sesuai dengan latar belakang penelitian maka dirumuskan dengan kalimat apakah dengan menggunakan supervisi bersahabat mampu meningkatkan kualitas pembelajaran guru, sehingga mempunyai tujuan untuk mendeskripsikan supervisi bersahabat dalam meningkatkan kualitas pembelajaran guru.

\section{METODE PENELITIAN}

Penelitian ini dilakukan di SD Negeri 21 Pekanbaru yang terletak di jalan Pahlawan Kerja nomor 13A kelurahan Maharatu kecamatan Marpoyan Damai, tepatnya pada semester ganjil bulan September tahun pelajaran 2019/2020. Waktu pelaksanaan penelitian dilaksanakan pada hari Sabtu tanggal 18 - 22 Januari 2020 untuk siklus I, dan tanggal 27 - 30 Januari 2020 untuk siklus II. Lama penelitian dimulai dari persiapan sampai pelaporan yaitu satu bulan yaitu dimulai pada pertengahan bulan Januari sampai dengan pertengahan bulan Februari 2020. Subjek penelitian ini adalah guru kelas VI di SD Negeri 21 Pekanbaru yang berjumlah 3 orang. Sedangkan objek penelitian ini adalah kualitas pembelajaran guru kelas VI.

Metode penelitian yang dilakukan adalah penelitian tindakan sekolah (PTS). Penelitian tindakan sekolah merupakan suatu upaya untuk mencermati kegiatan proses pendidikan di sekolah dengan memberikan suatu tindakan yang sengaja dilakukan. Tindakan tersebut untuk memperbaiki dan meningkatkan kualitas proses pendidikan dan pembelajaran di sekolah (Arikunto, 2009). Untuk menentukan keberhasilan tindakan penelitian tindakan sekolah ini, perlu dibuat indikatorindikator keberhasilan penelitian tindakan sekolah ini. Adapaun indikator keberhasilan tindakan PTS ini adalah seperti yang tertuang dalam tabel berikut:

Tabel 1. Indikator Keberhasilan PTS

\begin{tabular}{ccc}
\hline Indikator keberhasilan PTS & \multicolumn{1}{c}{ Rincian Sub Indikator } \\
& Guru Yang Kualitas Pembelajarannya Meningkat (diatas 75\%) \\
\hline Semakin berkualitasnya & - & Perangkat pembelajaran lengkap \\
pembelajaran yang dilakukan & - Menggunakan Media/Alat Peraga \\
& - Menggunakan model pembelajaran yang inovatif \\
& - Terciptanya suasana pembelajaran yang PAIKEM \\
& - Siswa tidak mengantuk / bermain sendiri \\
\hline
\end{tabular}


Data yang telah didapatkan dengan menggunakan instrumen observasi dan wawancara oleh peneliti selama proses kegiatan supervisi dianalisis data supervisi administrasi pembelajaran dan supervisi pelaksanaan kegiatan pembelajaran menggunakan rumus sebagai berikut :

$$
\mathrm{NA}=\frac{J S}{S M} \mathrm{X} 100
$$

Keterangan :

NA = Nilai Akhir Supervisi

JS = Jumlah Skor yang diperoleh

$\mathrm{SM}=$ Skor Maksimal

Tabel 2. Interval Kriteria Nilai Akhir Supervisi

\begin{tabular}{cc}
\hline \% Interval & Kategori \\
\hline $91-100$ & Amat baik \\
$81-90$ & Baik \\
$71-80$ & Cukup \\
Kurang dari 71 & Kurang \\
\hline
\end{tabular}

(Zarmalis, 2020)

\section{HASIL DAN PEMBAHASAN}

Tindakan yang dilaksanakan dalam penelitian ini adalah melaksanakan penerapan kegiatan supervisi kelas bersahabat terhadap majlis guru khusunya guru kelas VI SD Negeri 21 Pekanbaru. Penelitian dilaksanakan menurut desain Penelitian Tindakan Sekolah (PTS) yang terdiri dari dua siklus, setiap siklus terdiri dari empat kali pertemuan. Pelaksanaan tindakan yang dilakukan dengan menggunakan supervisi kelas bersahabat model bimbingan dan dengan jeda waktu yang telah ditentukan dapat diperoleh hasil yang memuaskan. Hal ini terlihat dengan adanya peningkatan persentase indikator keberhasilan PTS ini.

Pada tahap persiapan, sebelum melaksanakan kegiatan supervisi kelas bersahabat, peneliti telah mensosialisasikan rencana kegiatan penelitian tindakan sekolah kepada warga sekolah terutama kepada majlis guru SD Negeri 21 Pekanbaru sekaligus memberikan undangan pelaksanaan presentasi kegiatan supervisi dan mempersiapkan segala peralatan dan perlengkapan yang dibutuhkan.Pada siklus pertama dilakukan empat kali pertemuan dengan rincian pertemuan sebagai berikut :

1. Pertemuan pertama, penyajian materi yang meliputi :

Penjelasan makna supervisi kelas bersahabat.
Penjelasan alur dan prosedur pelaksanaan supervisi kelas.

Pemberian jadwal supervisi kelas bersahabat.

2. Pertemuan kedua, pelaksanaan supervisi di kelas VIA

3. Pertemuan ketiga, pelaksanaan supervisi di kelas VIB

4. Pertemuyan keempat, pelaksanaan supervisi di kelas VIC

Supervisi kelas bersahabat di masingmasing kelas VI. Supervisi diawali di kelas VIA. Sebelum melaksanakan supervisi di kelas VIA, peneliti bersama guru telah melakukan diskusi tentang materi, membantu persiapan guru mengajar, meyakinkan pada guru bahwa posisi peneliti bukan sebagai supervisor, tetapi memberikan teknis bantuan yang diperlukan guru, dan sebagai tim pengajar bersama guru. Sehingga diharapkan supervisi terkesan tidak menegangkan, tidak kaku, dan lebih bersahabat. Pagi hari setelah siswa berbaris, guru masuk kelas bersama peneliti. Guru menjelaskan kepada siswa bahwa keberadaan peneliti akan membantu proses pembelajaran sehingga siswa tidak bingung dan bertanya-tanya. Sambil menjalankan perannya, peneliti tidak lupa membuat catatan-catatan kecil tentang kekurangan dan kelebihan selama proses pembelajaran berlangsung. Setelah kegiatan supervisi selesai, peneliti merefleksi tentang kegiatan yang telah dilakukan, memberikan apresiasi terhadapa 
kegiatan guru yang postif, menjelaskan juga kelemahan apa yang terjadi, dan memberikan saran terhadap masalah-masalah yang menjadi prioritas dalam pembelajaran.

Pada tahap pengamatan terhadap pelaksanaan tindakan yang menitikberatkan pada peningkatan kualitas pembelajaran sebagai akibat diadakannya kegiatan supervisi kelas bersahabt yang telah dilakukan. Tujuan dilaksanakan pengamatan adalah untuk mengetahui kegiatan mana yang patut untuk dipertahankan, diperbaiki, ataupun dihilangkan sehingga pembinaan kegiatan supervisi kelas bersahabat di sekolah benar-benar berjalan sesuai dengan tujuan yang ada dan mampu meningkatkan kualitas pembelajaran bagi guru kelas VI. Setiap kegiatan guru juga diobservasi sesuai dengan aspek yang telah ditentulkan dalam instrument pemantauan kegiatan guru selama proses pembelajaran berlangsung.

Refleksi siklus pertama dilakukan untuk mengetahui kelemahan yang dialami pada saat proses pelaksanaan kegiatan supervisi kelas bersahabat pada siklus I untuk kemudian dilakukan perbaikan pada siklus berikutnya. Adapun refleksi siklus I adalah sebagai berikut: Pada siklus pertama, guru dan siswa masih tampak kaku karena ini merupakan supervisi perdana yang dilakukan. Guru dan siswa belum terbiasa dengan adanya kehadiran peneliti di dalam kelas. Kegiatan guru pun masih belum maksimal, sehingga peneliti memberikan saran dan masukan agar tercapai apa yang telah diharapkan dan diperbaiki pada siklus kedua. Pada siklus kedua kesiapan mental dan fisik guru sudah maksimal.Siswa pun sangat bersemangat menghadapai pembelajaran walaupun dengan adanya kehadiran peneliti di dalam kelas. Hal ini dikarenakan guru sudah terbiasa dengan kegiatan ini dan merasa kegiatan ini sangat bermanfaat, sehingga mereka menilai supervisi yang dilakukan untuk meningkatkan kualitas pembelajaran di kelas.

Supervisi kelas berdampak positif terhadap tingkat persiapan guru dalam menyusun dan menggunakan perangkat pembelajaran, yang otomatis membuat guru yang disupervisi menggunakan inovasi pembelajaran dengan metode/ model-model pembelajaran yang tidak konvensional lagi, sehingga terjadi peningkatan kualitas pembelajaran. Pada setiap siklus mengalami peningkatan, seperti tampak dalam gambar berikut.

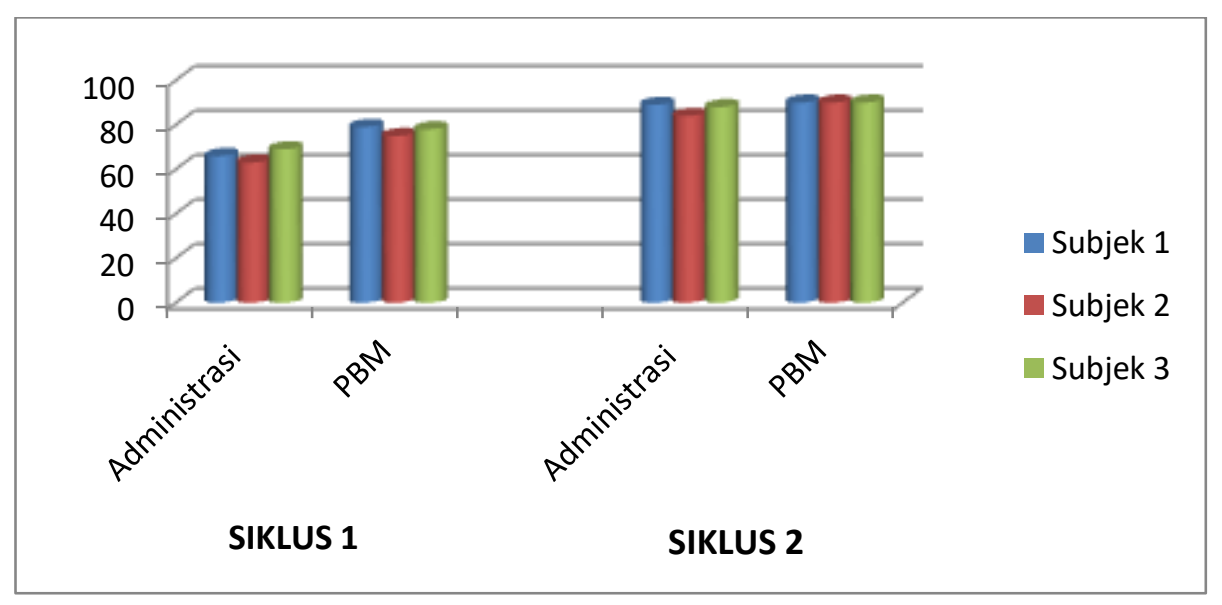

Gambar 1. Grafik Peningkatan Kualitas Pembelajaran Siklus 1 Ke Siklus 2

\begin{abstract}
Berdasarkan gambar 1 dapat dilihat bahwa terjadi peningkatan pada administrasi pembelajaran guru dari siklus satu ke siklus dua.
\end{abstract}

Disamping itu juga terjadi peningkatan pelaksanaan pembelajran dan kualitas pembelajaran dari siklus I ke siklus II. Hasil 
penelitian menunjukkan bahwa kegiatan supervisi kelas bersahabat berpengaruh positif terhadap kualitas pembelajaran yang dilakukan oleh guru. Kelengkapan administrasi pembelajaran yang dimiliki guru pada siklus I rata-rata nilainya adalah 66 dengan kategori kurang, sedangkan kelengkapan administrasi pembelajaran yang dimiliki guru pada siklus II rata-rata nilainya adalah 87 dengan kategori amat baik. Pada kegiatan pelaksanaan pembelajaran yang dilakukan guru di siklus I rata-rata nilainya adalah 77.33 dengan kategori cukup, meningkat pada siklus II dengan rata-rata nilai menjadi 90 dengan kategori baik.

Keberhasilan tindakan ini disebabkan oleh pemahaman secara menyeluruh tentang kualitas pembelajaran sangat diperlukan. Dengan pemahaman yang baik, maka proses pembelajaran akan dilaksanakan dengan baik sehingga kulaitas pembelajaran juga sangat baik (Purwanto, 1987). Mengoptimalkan pemahaman guru terhadap pembelajaran yang berkualitas melalui pembinaan intensif dalam bentuk kegiatan supervisi kelas bersahabat menunjukkan pada metode kooperatif konsulatif dimana diharapkan para guru bersama kepala sekolah saling berdiskusi, saling membantu, saling bekerja sama, dan saling berkonsultasi secara aktif (Pidarta, 1999). Aktivitas ini akan membantu para guru dalam menyajikan pembelajaran yang berkulitas di sekolah. Kaitannya dengan pembinaan melalui supervisi kelas bersahabat, maka penelitian ini juga sesuai dengan apa yang dikatakan oleh Neagley yang mendefinisikan supervisi sebagai setiap layanan kepada guru-guru yang bertujuan menghasilkan perbaikan instruksional untuk meningkatkan kualitas pembelajaran (Sungep, 2019).

$\begin{array}{cccc}\text { Peran } & \text { supervisi } & \text { kepala } & \text { sekolah } \\ \text { memberikan } & \text { masukan terhadap } & \text { kualitas }\end{array}$ menggunakan metode supervisi bersahabat terlihat lebih efektif dibandingkan dengan supervisi yang lainnya. Supervisi ini memberikan kontrol kepada guru dalam meningkatkan pembelajaran sehingga tidak melakukan penyimpangan terhadap proses pembelajaran (Suryani, 2015) karena guru merupakan profesi guru saat itu bagaikan seorang pejabat publik yang memiliki kharisma baik bagi dirinya maupun bagi keluarganya. Masyarakat selalu memperhatikan setiap tindak tanduk mereka dalam berinteraksi dengan lingkungan. Citra ini terbangun karena seorang guru benar-benar menjaga integritas dan kredibilitasnya. Ia tidak hanya mengajar di depan kelas, tapi juga mendidik, membimbing, menuntun, dan membentuk karakter moral yang baik bagi siswasiswanya (Natsir, 2007). Sehingga kepala sekolah jangan menjadikan guru sebagai bawahan akan tetapi dibuat menjadi kolega sehingga mampu meningkatkan kualitas pembelajaran di kelas tanpa ada paksaan.

Kompetensi guru merupakan perpaduan antara kemampuan personal, keilmuan, teknologi, sosial, dan spiritual yang secara menyeluruh membentuk kompetensi standar profesi guru. Seorang guru membutuhkan kompetensi yang baik sehingga dapat mengembangkan dan menyajikan materi pelajaran yang aktual dengan menggunakan berbagai pendekatan, metoda, dan teknologi pembelajaran terkini di sekolah, yang akan berdampak positif bagi peningkatan proses pembelajaran itu sendiri, serta dapat menghasilkan mutu pendidikan yang tinggi pula (Mulyasa, 2007; Permana, 2017).

\section{SIMPULAN DAN REKOMENDASI}

Berdasarkan hasil analisis hasil tindakan yang telah dilakukan, maka dapat disimpulkan kegiatan supervisi kelas bersahabat dapat meningkatkan kualitas pembelajaran yang dilakukan oleh guru kelas VI, persentase rata-rata perangkat/ administrasi pembelajaran yang dimiliki guru mengalami peningkatan dari siklus I dengan persentase $66 \%$, meningkat menjadi $87 \%$. Persentase pelaksanaan pembelajaran yang telah dilakukan guru juga mengalami peningkatan dari siklus I ke siklus II. Persentase rata-rata pelaksanaan pembelajaran yang dilakukan guru pada siklus I adalah $77 \%$ meningkat menjadi $90 \%$ pada siklus II. Majlis guru SD Negeri 21 Pekanbaru memberikan respon yang sangat positif terhadap kegiatan supervisi kelas bersahabat yang telah dilakukan.

Berdasarkan kesimpulan di atas, maka disarankan beberapa hal sebagai berikut : 
1. Para guru sebaiknya membuat dan melengkapi administrasi pembelajaran agar hassil belajaran dan kualitas pembelajaran menjadi maksimal.

2. Kepala sekolah sebagai supervisor di sekolah, harus membiasakan diri dan majlis guru untuk mengembangkan peningkatan budaya mutu sekolah sehingga target dalam meningkatkan mutu pendidikan dapat tercapai.

3. Pembinaan guru melalui kegiatan supervisi akademik, dapat dijadikan salah satu alternatif meningkatkan kualitas pembelajaran di sekolah.

\section{DAFTAR PUSTAKA}

Arikunto, S. (2009). Majemen Pendidikan. Yogyakarta: Aditya Media.

Arikunto, S. (2009). Penelitian Tindakan Kelas. Yogyakarta: Aditya Media.

Danumihardja, M. (2009). Supervisi Pendidikan. http://tenaga-kependidikan.

blogspot.co.id/2009/03/supervisi-

pendidikan.html

Mulyasa, E. (2003). Manajemen Berbasis Sekolah, Konsep, Strategi dan Implementasi. Bandung: Rosda Karya.

Mulyasa, E. (2007). Menjadi Guru Profesional Menciptakan Pembelajaran Kreatif dan Menyenangkan. Bandung: Rosdakarya.

Mulyana. (2002). Manajemen Berbasis Sekolah, Konsep Strategi dan Implementasi. Bandung: PT Remaja Rosdakarya.

Natsir, N. F. (2007). Peningkatan Kualitas Guru dalam Perspektif Pendidikan Islam. EDUCATIONIST, 1(1), 20-27.

Olivia, P. F. (1984). Supervision for Today's School. New York: Longman.

PSBG. (2008). Supervisi Bersahabat. [onine] 28 Juli

http://apakabarpsbg.wordpress.com/2008/0 5/21/teknik-baru-supervisi-kelasyanglebih-bersahabat/.

Purwanto, N. (1987). Administrasi dan Supervisi Pendidikan. Bandung: Remaja Rosda Karya.

Pidarta, M. (1999). Pemikiran Tentang Supervisi Pendidikan. Jakarta: Bumi Aksara.

Permana, N. S. (2017). Peningkatan Mutu Tenaga Pendidik Dengan Kompetensi dan
Sertifikasi Guru. STUDIA DIDAKTIKA: Jurnal Ilmiah Bidang Pendidikan, 11(1), 1- 8 .

Rachmawati, T. (2016). Supervisi Pendidikan Sebagai Upaya Meningkatkan Kinerja Guru. Coopetition, VII (1), 43 - 52 .

Slameto. (2016). Supervisi Pendidikan Oleh Pengawas Sekolah. Kelola Jurnal Manajemen Pendidikan, 3 (2), 192-206.

Soepardi, Imam. (2000). Dasar-Dasar Administrasi Pendidikan. Jakarta: Depdikbud.

Sungep. (2019). Pelaksanaan Supervisi Akademik untuk Meningkatkan Kompetensi Guru dalam Menyusun Tes Hasil Belajar Berbasis Keterampilan Berpikir Kritis. Jurnal PAJAR (Pendidikan dan Pengajaran), 3(6), 1332-1340. DOI : http://dx.doi.org/10.33578/pjr.v3i6.7896.

Suryani, C. (2015). Implementasi Supervisi Pendidikan dalam meningkatkan Proses Pembelajaran di MIN Sukadamai Kota Banda Aceh. Jurnal Ilmiah Didaktika, 16(1), 23 - 42.

Tatang. (2016). Supervisi Pendidikan. Solo: Pustaka Setia.

Zarmalis. (2020). Optimization Of Academic Supervision To Improve Teacher Ability In Class Management. Jurnal PAJAR (Pendidikan dan Pengajaran), 4(1), 219233. DOI http://dx.doi.org/10.33578/pjr.v4i1.7930. 